\title{
UM ESTUDO SOBRE A ATUAÇÃO DA CESP FRENTE AOS IMPACTOS SOCIOAMBIENTAIS CAUSADOS PELA USINA HIDRELÉTRICA DE PORTO PRIMAVERA
}

\author{
Amanda Grazielly Branquinho Gross
}

Universidade do Oeste Paulista - UNOESTE, MBA em Gestão Ambiental Empresarial, Presidente Prudente, SP. E-mail: amandagross@hotmail.com

\section{RESUMO \\ Com o avanço econômico, a utilização de energia elétrica foi intensificada para materializar as necessidades e desejos humanos, demandando a estruturação de usinas hidrelétricas, as quais expressam benefícios, mas também acarretam uma sucessão de adversidades ambientais. $O$ presente trabalho tem enfoque sobre a atuação da CESP em face dos impactos socioambientais causados pela Usina Hidrelétrica de Porto Primavera. O objetivo deste estudo foi exprimir e constatar a materialidade dos instrumentos de avaliação e gestão ambiental legalmente exigidos, atentando-se aos danos e providências tomadas e refletidas às esferas atingidas por esse empreendimento. Os resultados revelaram a ponderância entre energia elétrica, meio ambiente e sustentabilidade; os mecanismos legais aplicados à organização; a dimensão das consequências socioambientais e a executividade das medidas propostas pela Companhia, insuficientes para um alinhamento real. Conclui-se que os prejuízos provados nos diversos cenários são infindos e a responsabilidade empresarial e reparações, não serão atenuados em sua plenitude. \\ Palavras-chave: Usinas Hidrelétricas, Procedimentos Licenciatórios, Impactos Socioambientais, Medidas Compensatórias. \\ A STUDY ON THE ACTION OF CESP IN RESPECT OF THE SOCIO-ENVIRONMENTAL IMPACTS CAUSED BY THE HYDROELECTRIC POWER PLANT OF PORTO PRIMAVERA}

\begin{abstract}
With the economic advance, the use of electric energy was intensified to materialize the human needs and desires, demanding the structuring of hydroelectric plants, which express benefits, but also entail a succession of environmental adversities. The present work focuses on the performance of CESP in the face of the socioenvironmental impacts caused by the Porto Primavera Hydroelectric Power Plant. The objective of this study was to express and verify the materiality of the instruments of environmental assessment and management legally required, taking into account the damages and measures taken and reflected to the areas affected by this enterprise. The results revealed the importance of electricity, environment and sustainability; the legal mechanisms applied to the organization; the size of the socio-environmental consequences and the implementation of the measures proposed by the Company, insufficient for real alignment. It is concluded that the proven damages in the various scenarios are unfinished and corporate responsibility and reparations will not be completely mitigated.

Keywords: Hydroelectric Power Plants, Licensing Procedures, Socioenvironmental Impacts, Compensatory Measures.

\section{INTRODUÇÃO}

Com o advento das civilizações e da globalização, vigorosamente com a Revolução Industrial, privilegiou-se o avanço econômico e o sistema capitalista, para tanto, investiu-se na


evolução dos processos produtivos e consumeristas, intensificando a utilização de energia, sendo necessária a estruturação de usinas hidrelétricas.

Os benefícios são expressivos, aproximadamente, em todas as esferas, entretanto, tal modalidade de geração energética requisita amplos investimentos, engloba extensos territórios e acarreta uma sucessão alarmante de detrimentos ambientais.

O Brasil, país rico em recursos naturais, é reconhecido internacionalmente por sua legislação protetiva, uma das mais rígidas, completas e avançadas (TRENNEPOHL, 2017), tendo em vista a ampla abrangência (recursos hídricos, resíduos sólidos, fauna e flora, entre outros) dentre Constituição Federal e leis esparsas.

Os instrumentos de avaliação e gestão ambiental empresarial foram os recursos encontrados e normatizados, para que os empreendimentos, em cumprimento de seu papel, proporcionassem a sequência de suas atividades e do progresso, sem prejudicar maximamente o meio ambiente e a sociedade.

A problemática está quando as organizações adotam e/ou otimizam suas ferramentas apenas, em submissão legal, como um mecanismo de compensação, a fim de conter ou converter os danos provocados por seu exercício, por isso, indaga-se: Por ocasião da observância dos instrumentos de avaliação e gestão ambiental, as medidas mitigadoras e compensatórias executadas pela Companhia Energética de São Paulo (CESP) atingiram as expectativas delineadas frente aos impactos causados pela Usina Hidrelétrica de Porto Primavera?

Para tanto, o objetivo deste artigo é apresentar as informações contidas nos instrumentos de avaliação e gestão ambiental da CESP, entre eles encontram-se o licenciamento ambiental e suas licenças, o Estudo de Impacto Ambiental (EIA) e o Relatório de Impacto ao Meio Ambiente (RIMA), obrigatórios à implantação e as atividades da Usina Hidrelétrica de Porto Primavera.

Especifica-se, objetivamente, a constatação da materialidade dos instrumentos, contemplando as adversidades e as providências de compensação socioambientais legalmente exigidas, bem como a apuração das conclusivas documentadas refletidas à realidade.

Desta forma, revela-se patente a pretensão da pesquisa, em uma análise concisa, oportunizar a conscientização e esclarecimentos às comunidades leigas e especialistas, consequentemente, vitimadas e/ou interessadas no assunto, sobre a percepção, políticas e ações desempenhadas pela empresa como um possível ressarcimento à afronta ao bem comum.

\section{METODOLOGIA}

A presente pesquisa caracteriza-se como básica. Segundo Lakatos e Marconi (2001), esta pesquisa anseia apresentar novos conhecimentos e propagar as instruções científicas com o entendimento de fenômenos, sem apreensão imediata quanto às aplicações e influências práticas sobre determinado tema.

Para a exposição do assunto empregou-se a metodologia dedutiva, concretizada através de pesquisa bibliográfica e análise documental, já que "abrange toda bibliografia já tornada pública em relação ao tema estudado, desde publicações avulsas, boletins, jornais, revistas, livros, pesquisas, monografias, teses, materiais cartográficos, etc." (LAKATOS e MARCONI, 2001, p. 183).

A pesquisa bibliográfica foi realizada através de teses de doutoramento de estudiosos convertidas em livros, anuários energético (EPE) e corporativo (CESP), publicação científica acerca da unidade hidrelétrica de Porto Velho/RO, além da legislação pátria, dentre Constituição Federal, Política Nacional do Meio Ambiente e Resolução do Conselho Nacional do Meio Ambiente (CONAMA), aprofundando a compreensão de conceitos, características e argumentos.

Já a análise documental se efetivou em função dos instrumentos de avaliação e gestão ambiental, quais sejam: as licenças que compõem o licenciamento ambiental, em especial as licenças de operação, o Estudo de Impacto Ambiental (EIA) e o Relatório de Impacto ao Meio 
Ambiente (RIMA), documentos que concentram os dados da CESP para a construção e operação da Usina Hidrelétrica de Porto Primavera (Engenheiro Sérgio Motta), fixada na bacia do Rio Paraná, trazidos ao público por meio do Relatório Anual de Responsabilidade Socioambiental e Econômico-Financeiro de 2015 à Agência Nacional de Energia Elétrica (ANEEL).

Com relação à abordagem, a pesquisa é classificada como qualitativa, onde "o autor vai descrever um problema de pesquisa que possa ser melhor compreendido ao explorar um conceito ou fenômeno" (CRESWELL, 2007, p. 88).

Ademais, centra-se em uma pesquisa de campo para levantamento, coleta e análise de dados, atentando-se ao conhecimento de Creswell (2007, p. 189) de que "a ideia por trás da pesquisa qualitativa é selecionar propositadamente participantes ou locais (ou documentos, ou materiais gráficos) mais indicados para ajudar o pesquisador a entender o problema e a questão de pesquisa", de modo a imprimir a real situação ante aos problemas inquiridos até alcançar os propósitos almejados.

A participação da empresa, bem como de gestores e demais envolvidos com a temática envolve encontros, entrevistas e aplicação de questionários para esclarecimentos, organização, seleção e preparação das informações contidas nos procedimentos licenciatórios escriturados junto ao Instituto Brasileiro do Meio Ambiente e dos Recursos Naturais Renováveis (IBAMA) e órgãos ambientais.

\section{MATRIZ ENERGÉTICA E SUSTENTABILIDADE}

Sob a ótica mundial, a energia elétrica está associada à expansão econômica, sobrevivência e benefícios para a sociedade. O Brasil, abastado de recursos hídricos, iniciou a construção de usinas hidrelétricas ao findar do século XIX, apesar disso, fora impulsionada em meados da década de 1970 , em atenção aos vestígios de crise petroleira, até então fonte precípua de energia nacional (COSTA, 2010).

Logicamente, o intento intrínseco estatal era potencializar o desenvolvimento e evitar prejuízos financeiros. Com o fortalecimento do comércio e a visão riqueza/poder houve maior investimento nos sistemas manufatureiros para materializar as necessidades, expectativas e anseios de consumo da humanidade (TRENNEPOHL, 2017), demandando uma aplicação considerável e estratégica de energia elétrica e, consequentemente, a edificação de novas usinas hidrelétricas, atualmente, responsáveis por $64 \%$ da geração elétrica no país (EPE, 2016).

O dispêndio progressivo e as consequências socioambientais decorrentes desta modalidade potencial e tradicional induziram a governança e a coletividade, em virtude da ovacionada necessidade de desenvolvimento sustentável, a adotarem uma política energética pautada em fontes renováveis diversas, alternativas e acessíveis ao mercado (COSTA, 2010), tais como a energia eólica, termoelétrica, nuclear, entre outras.

Deste modo, a inserção de matérias ambientais ao fornecimento de energia elétrica patrocina a disponibilidade futura e a constância da formação de processamento e funcionamento producente do país.

\section{LICENCIAMENTO AMBIENTAL E SUAS CARACTERÍSTICAS}

O meio ambiente é uma prerrogativa inalienável concernente a todos, à vista disso, requer, obrigatoriamente, a intervenção do Poder Público mediante um agrupamento de atos e providências disseminado pelos princípios e ordenamentos, visando à proteção do bem jurídico em sua diversidade (DESTEFENNI, 2004).

Com o arcabouço dos pressupostos de defesa ambiental e sua imposição pelas distintas legislações, sendo normas peculiares dos Estados, de comunidades de nações, ou ainda de tratados internacionais (TRENNEPOHL, 2017), os legisladores brasileiros introduziram aparatos 
para avaliação e gestão ambiental, afamados como recursos de comando e controle das instituições e seu funcionamento.

A operacionalização de políticas intercessoras foi definida através de Resoluções do Conselho Nacional do Meio Ambiente (CONAMA) e está distribuída nos âmbitos constitucional e infraconstitucional, inauguralmente no rol do artigo $9^{\circ}$ da Lei $n^{\circ} 6938 / 1981$, lei denominada Política Nacional do Meio Ambiente que tenciona "a preservação, melhoria e recuperação da qualidade ambiental propícia à vida, visando assegurar, no País, condições ao desenvolvimento socioeconômico, aos interesses da segurança nacional e à proteção da dignidade da vida humana", conforme transcrito em seu $2^{\circ}$ artigo (BRASIL, 1981).

O licenciamento ambiental, um dos instrumentos fundamentais da Política Nacional do Meio Ambiente e principal mecanismo de avaliação de impactos ecológicos, exprime seu conceito legal no artigo $1^{\circ}$, inciso I, da Resolução CONAMA $n^{\circ}$ 237/1997. Em síntese, o ilustre Destefenni (2004, p. 83) aclara que é o "procedimento administrativo que tramita perante órgãos ambientais, e que tem por objeto estabelecer as condições e os requisitos para o exercício de uma atividade ou de um empreendimento que possa provocar alguma degradação ambiental".

Em outras palavras, o licenciamento ambiental trata-se de um conjunto de etapas que alinha o processo administrativo, ambicionando a transmissão de uma licença ambiental, uma das fases do procedimento. Neste enfoque, o dispositivo supramencionado em seu inciso II, define por licença:

Ato administrativo pelo qual o órgão ambiental competente, estabelece as condições, restrições e medidas de controle ambiental que deverão ser obedecidas pelo empreendedor, pessoa física ou jurídica, para localizar, instalar, ampliar e operar empreendimentos ou atividades utilizadoras de recursos ambientais, consideradas efetiva ou potencialmente poluidoras ou daquelas que, sob qualquer forma, possam causar degradação ambiental. (BRASIL, 1997).

As licenças ambientais, previstas no artigo $8^{\circ}$ da Resolução CONAMA $n^{\circ}$ 237/1997, podendo ser outorgadas em apartado ou consecutivamente, são organizadas de três formas, quais sejam:

I - Licença Prévia (LP) - concedida na fase preliminar do planejamento do empreendimento ou atividade aprovando a sua localização e concepção, atestando a viabilidade ambiental e estabelecendo os requisitos básicos e condicionantes a serem atendidos nas próximas fases de sua implementação;

II - Licença de Instalação (LI) - autoriza a instalação do empreendimento ou atividade de acordo com as especificações constantes dos planos, programas e projetos aprovados, incluindo as medidas de controle ambiental e demais condicionantes, da qual constituem motivo determinante;

III - Licença de Operação (LO) - autoriza a operação da atividade ou empreendimento, após a verificação do efetivo cumprimento do que consta das licenças anteriores, com as medidas de controle ambiental e condicionantes determinados para a operação.

Ademais, o artigo 18 da mesma Resolução preconiza a validez de cada licença, a saber: a Licença Prévia estima até cinco anos; já à Licença de Instalação atribui-se mais um ano (seis anos); e a Licença de Operação computa de quatro a dez anos, sendo todas capazes de prorrogação, 
cassação ou revogação.

Chegado a este patamar, insta salientar que "é requisito indispensável ao licenciamento à elaboração de EIA-RIMA, ou seja, estudo prévio de impacto ambiental e respectivo relatório de impacto sobre o meio ambiente" (DESTEFENNI, 2004, p. 98).

$\mathrm{O}$ artigo 225, parágrafo $1^{\circ}$, inciso IV, da Carta Magna de 1988, postula o estudo precedente de impacto como aporte de apreciação das autorizações peticionárias, baseando-se em um "relatório ambiental, plano e projeto de controle ambiental, relatório ambiental preliminar, diagnóstico ambiental, plano de manejo, plano de recuperação de área degradada e análise preliminar de risco", narrados no artigo $1^{\circ}$, inciso III, da Resolução CONAMA n² 237/1997.

O Estudo de Impacto Ambiental (EIA) é uma subdivisão das Avaliações de Impacto Ambiental (ARONI, 2013), integrado por elementos minuciosos e técnicos em um documento de cunho formal e sigiloso, em respeito às indústrias e suas ações.

As catalogações conclusivas do EIA, os prováveis efeitos e soluções, vantagens e desvantagens da execução são expressos através do Relatório de Impacto ao Meio Ambiente (RIMA), um instrumento concatenado ao primeiro e, ambos formulados por profissionais multidisciplinares, a fim de traduzir fielmente o conteúdo e instituir medidas mitigadoras e restituidoras, materiais ou extrapatrimoniais, para a reparação da deterioração ecológica, conforme Aroni (2013, p. 26) classifica:

a) Restauração in situ (mesmo local) ou restauração natural: é aquela em que se busca recompor integralmente os bens afetados;

b) Compensação ecológica: prevista na Convenção da Biodiversidade, das quais o Brasil é signatário, é aquela em que se busca recuperar os danos causados naquela ou em outra área, mas ainda assim cumula-se indenização pecuniária pelos danos causados. A reparação pode ser in situ (mesmo local) ou por equivalência (em local diverso).

No tocante à competência para licenciar, compulsar o resguardo do meio ambiente e fiscalizar a efetivação de planos compensatórios, a Constituinte Federal estabelece a alçada comum e concorrente dos órgãos federativos neste ofício, isto posto, a Resolução CONAMA $n^{\circ}$ 237/1997 deslinda em seus artigos que:

Art. 40. Compete ao Instituto Brasileiro do Meio Ambiente e dos Recursos Naturais Renováveis - IBAMA, órgão executor do SISNAMA, o licenciamento ambiental, a que se refere o artigo 10 da Lei no 6.938, de 31 de agosto de 1981, de empreendimentos e atividades com significativo impacto ambiental de âmbito nacional ou regional, a saber:

I - localizadas ou desenvolvidas conjuntamente no Brasil e em país limítrofe; no mar territorial; na plataforma continental; na zona econômica exclusiva; em terras indígenas ou em unidades de conservação do domínio da União;

II - localizadas ou desenvolvidas em dois ou mais Estados;

III - cujos impactos ambientais diretos ultrapassem os limites territoriais do País ou de um ou mais Estados;

IV - destinados a pesquisar, lavrar, produzir, beneficiar, transportar, armazenar e dispor material radioativo, em qualquer estágio, ou que utilizem energia nuclear em qualquer de suas formas e aplicações, mediante parecer da Comissão Nacional de Energia Nuclear - CNEN;

V - bases ou empreendimentos militares, quando couber, observada a legislação específica. (BRASIL, 1997). 
No procedimento licenciatório, cabe ao IBAMA considerar questões ambientais em nível federal, em casos específicos, podendo delegar aos órgãos estaduais ou do Distrito Federal:

Art. 5o. Compete ao órgão ambiental estadual ou do Distrito Federal o licenciamento ambiental dos empreendimentos e atividades:

I - localizados ou desenvolvidos em mais de um Município ou em unidades de conservação de domínio estadual ou do Distrito Federal;

II - localizados ou desenvolvidos nas florestas e demais formas de vegetação natural de preservação permanente relacionadas no artigo 20 da Lei no 4.771, de 15 de setembro de 1965, e em todas as que assim forem consideradas por normas federais, estaduais ou municipais;

III - cujos impactos ambientais diretos ultrapassem os limites territoriais de um ou mais Municípios;

IV - delegados pela União aos Estados ou ao Distrito Federal, por instrumento legal ou convênio. (BRASIL, 1997).

Já aos organismos municipais incumbe licenciar sobre organizações e performance ecológicas in loco, além das solicitadas pelo Estado por recursos normativos ou convênios:

Art. 6o. Compete ao órgão ambiental municipal, ouvidos os órgãos competentes da União, dos Estados e do Distrito Federal, quando couber, o licenciamento ambiental de empreendimentos e atividades de impacto ambiental local e daquelas que Ihe forem delegadas pelo Estado por instrumento legal ou convênio. (BRASIL, 1997).

Diversas leis sistematizam acerca de sanções penais, civis e administrativas pela inobservância dos parâmetros primários acima expostos, tais casos decorrerão da conduta e tipologia nocivas ao meio ambiente, bem como do porte e capacidade empresarial da agressora.

Ante ao rigor do ordenamento jurídico e a instrução da sociedade, ultima-se que as instituições são, legalmente e economicamente, compelidas a avocar sua responsabilidade ambiental para perpetuar-se no mercado.

\section{O CASO DA CESP}

A CESP, uma das principais gerenciadoras de energia elétrica do Brasil, integra o quadro de entidades e atividades que se servem de insumos naturais e, sucessivamente, alteram o cenário ambiental preexistente em prol do crescimento econômico.

Sob o aspecto de instrumentos legais exigíveis, o empreendimento Engenheiro Sérgio Motta (Porto Primavera), instalado no município de Rosana/SP, e o seu funcionamento estão simétricos devido ao íntegro atendimento das imposições expressas e dos órgãos licenciadores. Este compromisso compõe os fundamentos de sua Política Ambiental (CESP, 2015).

A Usina Hidrelétrica de Porto Primavera no Rio Paraná trata-se de uma estruturação precedente a 1986, iniciada em junho de 1980 pela CESP, razão pela qual foi ajustada aos ofícios do Departamento de Avaliação de Impacto Ambiental (DAIA), Termos de Ajustamento de Conduta (TAC) celebrados com o Ministério Público Federal e Instituto Brasileiro do Meio Ambiente e dos Recursos Naturais Renováveis (IBAMA), tornando-se objeto de Regularização Ambiental pela ausência de leis acerca da temática na época.

Desta maneira, não houve a expedição de licenças prévia e de instalação. Das etapas do licenciamento, a normatização foi dada pela obtenção de licença de operação, escusa a presença de RIMA, todavia, a Companhia encaminhou aos órgãos estaduais competentes toda a 
caracterização da organização, bem como a exposição de impactos causados, as medidas protetivas ou formas de adoção.

Em 1994, após contínuos estudos realizados pela concessionária e técnicos-científicos, documentou-se o EIA, disposto em oito volumes, explanando sobre as características e interferências na climatologia, hidrologia, geologia, geomorfologia, pedologia, potencial agrícola das terras e recursos minerais perante os meios físico, biótico e socioeconômico das regiões afetadas.

Ante ao processo $n^{\circ}$ 02001.001247/92-97, o IBAMA, em 03 de novembro de 1998, deliberou a Licença de Operação $\mathrm{n}^{\circ}$ 024/1998, autorizando a manipulação da Usina e o enchimento do reservatório até a cota de $253 \mathrm{~m}$, estando sua validade condicionada ao cumprimento de medidas em prazos determinados.

O empreendimento passou a operar sob a Licença $n^{\circ} 121 / 2000$ para a cota de $257 \mathrm{~m}$, sendo periodicamente renovada até que o órgão licenciador se manifeste acerca de sua validez, consoante ao artigo 18 , parágrafo $4^{\circ}$ da Resolução CONAMA n² 237/1997.

Além disso, a Companhia protocolou junto ao IBAMA, em 27 de outubro de 2009, o Plano Ambiental de Conservação e Uso do Entorno de Reservatórios Artificiais - PACUERA, criado a partir da Resolução CONAMA n 302/2002 e Termo de Referência expedido pelo IBAMA (CESP, 2015).

Resumidamente, os textos do EIA-RIMA apontam os principais impactos provocados pelo empreendimento e desempenho da Usina Hidrelétrica de Porto Primavera, também expressos no Relatório Anual de Responsabilidade Socioambiental e Econômico-Financeiro de 2015 à Agência Nacional de Energia Elétrica (ANEEL), como apresentado no Quadro 01:

Quadro 01: Principais impactos causados pela UHE Sérgio Motta (Porto Primavera) PRINCIPAIS IMPACTOS CAUSADOS PELA UHE SÉRGIO MOTTA (PORTO PRIMAVERA)

Impacto físico pela exploração de áreas de empréstimo para utilização como canteiro de obras; Impacto causado às comunidades florestais; Impacto causado à fauna silvestre, grandes felíneos e cervo-do-pantanal; Impacto sobre porções significativas de ecossistemas da região, notadamente nos varjões do Rio Paraná, implicando na redução de espécies, incluindo algumas ameaças de extinção;

Impacto sobre as atividades de extração de argila, areia e cascalho nas áreas inundadas; Impacto sobre a população residente nas áreas necessárias à implantação do empreendimento em termos de perda de patrimônio e atividade econômica exercida à época;

Impactos causados pelo empreendimento sobre os meios físico, biótico e socioeconômico; Impacto sobre áreas afetadas por processos de instabilização ou potencialmente instáveis; Impacto sobre a fauna aquática e modificações na atual arte de pesca e equipamentos utilizados; Impacto causado às condições de vida das famílias reassentadas.

Fonte: $\operatorname{CESP}(2015$, p. 78).

Resta ilustrar, de maneira mais clara e direta, as consequências ocasionadas: alteração da qualidade e dos cursos da água; assoreamentos e erosões; atenuação de atividades de subsistência; extermínio de ilhas, margens e terras pertencentes aos estados de São Paulo e Mato Grosso do Sul; desestruturação social, cultural e sentimental das populações atingidas; perturbações irreversíveis na fauna e flora regional; desvio da rota de peixes; mudança climática, dentre outras. 
Partindo da premissa que as instituições devem se responsabilizar por todas as perturbações causadas, torna-se cada vez mais comum, empresas adotarem atitudes sustentáveis e sistemas gestacionais a partir de impactos gerados na tríade social, ambiental e econômica.

A atuação da Companhia Energética de São Paulo frente às significativas implicações ambientais foi direcionada como uma via de prevenção, equiparação ou reversão por meio de ações e medidas compensatórias, são elas:

Quadro 02: Resultados reais sobre as medidas mitigadoras e compensatórias propostas pela CESP

\begin{tabular}{|c|c|}
\hline MEDIDAS MITIGADORAS E COMPENSATÓRIAS PROPOSTAS & RESULTADOS REAIS \\
\hline $\begin{array}{l}\text { Implantar e executar o Programa de Reassentamento com todas as } \\
\text { famílias atingidas pela inundação }\end{array}$ & Executado totalmente \\
\hline $\begin{array}{l}\text { Construir residências definitivas e implantar infraestrutura } \\
\text { necessária dos reassentamentos rurais e urbanos para relocação } \\
\text { das famílias }\end{array}$ & Executado totalmente \\
\hline $\begin{array}{l}\text { Edificar e relocar os equipamentos de ensino (creches e escolas) e } \\
\text { templos religiosos }\end{array}$ & Executado totalmente \\
\hline $\begin{array}{l}\text { Edificar pontes, galerias, estradas, rede de energia elétrica e } \\
\text { hidráulica, redes de água, esgoto e águas pluviais }\end{array}$ & Executado totalmente \\
\hline $\begin{array}{l}\text { Implantar e executar o Programa de Remanejo das populações } \\
\text { atingidas antes do enchimento do reservatório }\end{array}$ & Executado totalmente \\
\hline $\begin{array}{l}\text { Implantar, executar e monitorar o Programa de Relocação de } \\
\text { Comunidade Indígena junto a FUNAI }\end{array}$ & Executado total \\
\hline $\begin{array}{l}\text { Providenciar a transferência e adaptação das famílias sul-mato- } \\
\text { grossenses e paulistas atingidas pela inundação }\end{array}$ & Executado totalmente \\
\hline $\begin{array}{l}\text { Formar e garantir o estoque de argila para os oleiros de } \\
\text { Brasilândia/MS e Bataguassu/MS }\end{array}$ & Executado total \\
\hline $\begin{array}{l}\text { Implantar e executar o Programa de Reinserção Produtiva do Setor } \\
\text { Cerâmico Oleiro para oleiros afetados }\end{array}$ & Executado totalmente \\
\hline $\begin{array}{l}\text { Implantar e executar o Programa de Desmonte e Desinfecção das } \\
\text { áreas inundadas }\end{array}$ & Executado totalmente \\
\hline $\begin{array}{l}\text { Implantar e executar o Programa de Apoio à Mão-de-Obra aos } \\
\text { atingidos }\end{array}$ & Executado \\
\hline Relocar as áreas de lazer de Panorama/SP e Presidente Epitácio/SP & Executado totalmente \\
\hline $\begin{array}{l}\text { Implantar áreas de lazer em Anaurilândia/MS, Bataguassu/MS, } \\
\text { Brasilândia/MS, Santa Rita do Pardo/MS, Três Lagoas/MS e } \\
\text { Paulicéia/SP }\end{array}$ & Executado totalmente \\
\hline $\begin{array}{l}\text { Implantar Pontos de Embarque e Desembarque para Pescadores } \\
\text { ao longo do reservatório }\end{array}$ & Executado totalmente \\
\hline Proceder o resgate arqueológico & Em fase de execução \\
\hline Implantar e executar Programas e Ações de Educação Ambiental & Em fase de execução \\
\hline Construir Centros de Educação Ambiental & Executado parcialmente \\
\hline $\begin{array}{l}\text { Resgatar, soltar, relocar e monitorar a fauna através do Programa } \\
\text { de Operação Resgate de Fauna das ilhas e margens do reservatório }\end{array}$ & Executado totalmente \\
\hline Implantar bases de resgate da fauna & Executado totalmente \\
\hline $\begin{array}{l}\text { Enviar a fauna não-relocada para instituições científicas sob } \\
\text { autorização do IBAMA }\end{array}$ & Executado totalmente \\
\hline Orientar as comunidades sobre a proibição da caça e pesca & Executado totalmente \\
\hline
\end{tabular}




\begin{tabular}{|c|c|}
\hline $\begin{array}{l}\text { Providenciar obras do sistema de tratamento do esgoto de } \\
\text { Panorama/SP }\end{array}$ & $\mathrm{e}$ \\
\hline $\begin{array}{l}\text { Relocar a infraestrutura portuária de Presidente Epitácio/SP e } \\
\text { Panorama/SP antes do enchimento do reservatório }\end{array}$ & \\
\hline Implantar e executar o Programa de Unidades de Conservação & \\
\hline $\begin{array}{l}\text { Adquirir áreas para criação de unidades de conservação nos } \\
\text { estados de São Paulo e Mato Grosso do Sul }\end{array}$ & \\
\hline $\begin{array}{l}\text { r e executar o Programa de Controle da Proliferação das } \\
\text { quáticas }\end{array}$ & $\begin{array}{l}\text { Em fase } \\
\text { monitoramento }\end{array}$ \\
\hline $\begin{array}{l}\text { Realizar os desmatamentos após autorização do IBAMA para } \\
\text { supressão de vegetação }\end{array}$ & \\
\hline $\begin{array}{l}\text { Implantar e executar o Programa de Proteção de Encostas } \\
\text { Marginais }\end{array}$ & $\begin{array}{l}\text { execução e } \\
\text { o }\end{array}$ \\
\hline $\begin{array}{l}\text { Implantar e executar o Programa de Controle de Erosão e } \\
\text { Assoreamento nas áreas de influência do reservatório }\end{array}$ & \\
\hline $\begin{array}{l}\text { executar e monitorar o Plano de Monitoramento do } \\
\text { eático }\end{array}$ & $\begin{array}{l}\text { Executado totalmente e } \\
\text { em fase de } \\
\text { monitoramento }\end{array}$ \\
\hline \begin{tabular}{|l} 
ísticas Limnológicas e de Qualidade da Água Superficial \\
\end{tabular} & $\begin{array}{l}\text { Em fase } \\
\text { monitoramento }\end{array}$ \\
\hline $\begin{array}{l}\text { r e executar Programas de Monitoramento para todos os } \\
\text { as ambientais }\end{array}$ & $\begin{array}{l}\text { Em fase } \\
\text { monitoramento }\end{array}$ \\
\hline $\begin{array}{l}\text { ar a faixa de preservação permanente no entorno do } \\
\text { atório }\end{array}$ & \\
\hline $\begin{array}{l}\text { ar e executar o Programa de Recuperação de Áreas } \\
\text { adas }\end{array}$ & \\
\hline $\begin{array}{l}\text { as áreas de interesse ambiental e matas ciliares para } \\
\text { la fauna e flora }\end{array}$ & \\
\hline 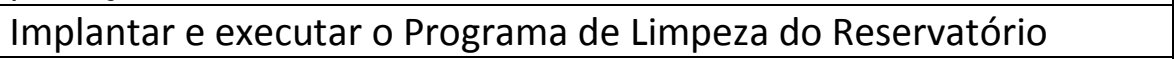 & \\
\hline rio & \\
\hline $\begin{array}{l}\text { Implantar e executar o Programa de Valorização da Memória } \\
\text { Regional }\end{array}$ & \\
\hline e executar o Programa do Banco Ge & \\
\hline e executar o Programa de Monitoramento de Macrófitas & \\
\hline $\begin{array}{l}\text { Implantar e executar o Programa de Monitoramento } \\
\text { Sedimentológico }\end{array}$ & $\begin{array}{l}\text { Em fase } \\
\text { monitoramento }\end{array}$ \\
\hline $\begin{array}{l}\text { e executar o Programa de Monitoramento da Ictiofauna } \\
\text { de espécies de peixes) }\end{array}$ & $\begin{array}{l}\text { Em fase } \\
\text { monitoramento }\end{array}$ \\
\hline $\begin{array}{l}\text { Implantar e executar o Programa de Controle e Monitoramento de } \\
\text { Poluição da bacia }\end{array}$ & $\mathrm{Em}$ \\
\hline $\begin{array}{l}\text { Implantar e executar o Programa de Fiscalização nas áreas de } \\
\text { resgate de fauna e flora }\end{array}$ & Exe \\
\hline $\begin{array}{l}\text { Implantar, executar e monitorar o Programa de Controle do } \\
\text { Mexilhão Dourado }\end{array}$ & $\begin{array}{l}\text { Em fase } \\
\text { monitoramento }\end{array}$ \\
\hline e executar & En \\
\hline
\end{tabular}

Fonte: Desenvolvido com base nas informações do RIMA/CESP 
Vinculados às resultantes do licenciamento ambiental, o IBAMA condicionou à CESP, o emprego das demais políticas legais. Em decorrência desta situação fática, a mesma vem adotando mecanismos alternativos de avaliação e gestão ambiental, até mesmo para facilitar o leilão das últimas unidades embaraçadas pelos procedimentos em execução e pendências ecológicas.

Oportunamente, a Companhia esforçando-se para o acompanhamento e conformidade legal, em dezembro de 2015, completou a implantação de um Sistema de Gestão Ambiental, exclusivamente, na Usina Hidrelétrica Engenheiro Sérgio Motta (Porto Primavera), através de "um conjunto de procedimentos com ênfase na sustentabilidade e foco na adoção de práticas que buscam reduzir ao máximo o impacto ambiental das atividades da Companhia" (CESP, 2015, p. 58).

Em atenção ao perfil energético-estratégico sustentável, a CESP juntamente com empresas cooperadas vem projetando também a geração de energia elétrica por meio de fontes eólicas e solares fotovoltaicas (CESP, 2015), iniciadas, antecipadamente, em março de 2014 na Usina de Porto Primavera.

\section{CONCLUSÃO}

O presente estudo envolveu a atuação da CESP frente aos impactos socioambientais causados pela Usina Hidrelétrica de Porto Primavera, de modo a relacionar a influência desta na sociedade e no meio ambiente e os instrumentos normativos de avaliação e gestão ambiental atinentes ao setor.

Ao discorrer sobre o tema, avaliou-se que a energia elétrica se tornou, indiscutivelmente, imperiosa para criação e sustentação do homem e das atividades financeiras pela infinidade de prestações positivas, esboçando a perspectiva de que, ante a sua ausência, seriam inconcebíveis a maximização do desenvolvimento, a sociedade moderna e as essencialidades vitais.

Por outro lado, como exposto ao longo do artigo, muitas peculiaridades precisam ser consideradas. Embora o abastecimento energético seja necessário e benéfico, a exploração procedente de qualquer recurso natural à sua produção, a demanda elevada e a má utilização desse bem subalterniza adversidades ecológicas, desde o seu planejamento até a sua operação geracional.

Diante da introdução e evidência de questões ambientais em dimensão universal, constatou-se a modificação de paradigmas na lógica financeira e a orientação por instrumentos e ações político-legais. Neste sentido, a economia nacional esforça-se ao ajuste do ordenamento jurídico e tendências, além de métodos eletivos e eficazes de gerenciamento para refletir a proteção ambiental, garantindo a disponibilidade para futuras gerações.

O licenciamento ambiental composto pelo Estudo de Impacto Ambiental (EIA), Relatório de Impacto ao Meio Ambiente (RIMA) e licenças são capazes de dirimir conflitos, visto que examinam os ambientes que serão afetados, os impactos causados e as possíveis resoluções preventivas, mitigadoras e/ou compensatórias, por esta razão, a CESP norteia o funcionamento da Usina Hidrelétrica de Porto Primavera por meio destes instrumentos de avaliação e gestão ambiental para a tomada de providências exigidas legalmente pelos órgãos licenciadores competentes.

Inegavelmente, a edificação e atuação da Usina com a barragem mais extensa do Brasil vitimaram várias populações sul-mato-grossenses e paulistas que ladeiam o Rio Paraná, acometidas de sequelas sociais, econômicas e ambientais, para tanto, a CESP efetuou e ainda efetua variáveis medidas em busca da restituição das características locais.

Com a realização da pesquisa compreendeu-se que, em aspectos materiais e quantitativos monetariamente, a CESP vêm cumprindo com as expectativas delineadas, todavia, os malfeitos ao meio ambiente são vistos como irreversíveis quanto à sua origem, naturalidade e diversidade, mesmo diante de todas as reparações e compensações realizadas. Conter estes danos foi uma 
impossibilidade percebida pela Companhia e pela coletividade, logo, as medidas adotadas foram, intuitivamente, para converter e/ou amenizar os impactos experimentados no campo socioambiental.

Ademais, as lesões sentimentais e históricas (identidades locais) são imensuráveis e não poderão ser neutralizadas em sua plenitude, disseminando uma ligeira desproporção entre a realidade e as conclusivas materializadas nos instrumentos estudados, os quais presumem os efeitos equiparatórios.

Acompanhando tais considerações, notou-se que o processo formador de conscientização/educação ambiental, a transição cultural, a implantação de instrumentos legais e alternativos e o investimento em fontes de energia renováveis contribuem para o ciclo de geração-consumo sustentável, atitudes adotadas pela CESP para estreitar ecologia e economia, consolidando sua responsabilidade.

O aperfeiçoamento do estudo torna-se relevante, uma vez que o presente artigo não exaure a temática e se retrata como uma contingência de aprimoramento dos mecanismos legais, seleção de políticas e ações socioambientais às gestões empresariais e planejamento incorporado de recursos naturais, potenciais provedores de energia elétrica, de modo a atenuar os desastres e fomentar a sustentabilidade.

\section{REFERÊNCIAS BIBLIOGRÁFICAS}

ARONI, R. L. Legislação Ambiental. Presidente Prudente: UNOESTE, 2013.

BRASIL. Constituição (1988). Constituição da República Federativa do Brasil. Brasília: Senado Federal, 1988.

. Lei ${ }^{\circ} 6938$ de 31 de agosto de 1981. Dispõe sobre a Política Nacional do Meio Ambiente, seus fins e mecanismos de formulação e aplicação, e dá outras providências. Disponível em: <http://www.planalto.gov.br/ccivil_03/leis/L6938.htm>. Acesso em: 09 mar. 2017.

- Ministério do Meio Ambiente. Resolução do Conselho Nacional do Meio Ambiente (CONAMA) $n^{\circ} 237$ de 19 de dezembro de 1997. Dispõe sobre a revisão e complementação dos procedimentos e critérios utilizados para o licenciamento ambiental. Disponível em:<http://www.mma.gov.br/port/conama/res/res97/res23797.html>. Acesso em: 09 mar. 2017.

COMPANHIA ENERGÉTICA DE SÃO PAULO - CESP. Relatório Anual de Responsabilidade Socioambiental e Econômico-Financeiro 2015. Disponível em: <http://site.cesp.com.br/Relat\%C3\%B3rio\%20Socioambiental\%202015_Portugu\%C3\%AAs_reduzid o.pdf>. Acesso em: 24 mar. 2017.

COSTA, G.B. Análise do Relatório do Impacto Ambiental das Usinas Hidrelétricas no Rio Madeira no Município de Porto Velho/RO. Disponível em: <http://www.anppas.org.br/encontro5/cd/artigos/GT14-344-287-20100902124004.pdf>. Acesso em: 30 mar. 2017.

CRESWELL, J. W. Projeto de pesquisa: método qualitativo, quantitativo e misto. 2. ed. Porto Alegre: Artmed, 2007.

DESTEFENNI, M. Direito Penal e Licenciamento Ambiental. São Paulo: Memória Jurídica, 2004. 
EMPRESA DE PESQUISA ENERGÉTICA - EPE. Ministério de Minas e Energia. Balanço Energético Nacional 2016 - $\quad$ Ano Base 2015. Disponível em: <https://ben.epe.gov.br/downloads/S\%C3\%ADntese\%20do\%20Relat\%C3\%B3rio\%20Final_2016_ Web.pdf>. Acesso em: 01 abr. 2017.

LAKATOS, E. M.; MARCONI, M. de A. Fundamentos metodologia científica. São Paulo: Atlas S.A, 2001.

THEMAG, ENGEA e UMAH. EIA/RIMA de Porto Primavera. São Paulo: CESP, 1994/1995.

TRENNEPOHL, T. Direito Ambiental Empresarial. 2. ed. São Paulo: Saraiva, 2017. 